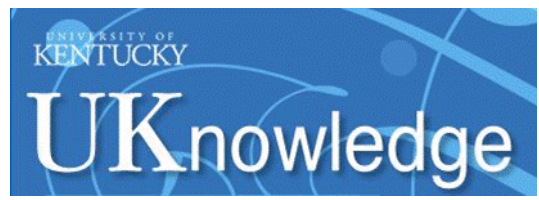

University of Kentucky

UKnowledge

Sanders-Brown Center on Aging Faculty

Publications

Aging

$5-8-2018$

\title{
Historical and Cross-Cultural Perspectives on Parkinson's Disease
}

Lee Xenakis Blonder

University of Kentucky, Ixblond@uky.edu

Follow this and additional works at: https://uknowledge.uky.edu/sbcoa_facpub

Part of the Alternative and Complementary Medicine Commons, History of Science, Technology, and Medicine Commons, Integrative Medicine Commons, Neuroscience and Neurobiology Commons, and the Social and Cultural Anthropology Commons

Right click to open a feedback form in a new tab to let us know how this document benefits you.

\section{Repository Citation}

Blonder, Lee Xenakis, "Historical and Cross-Cultural Perspectives on Parkinson's Disease" (2018).

Sanders-Brown Center on Aging Faculty Publications. 92.

https://uknowledge.uky.edu/sbcoa_facpub/92

This Review is brought to you for free and open access by the Aging at UKnowledge. It has been accepted for inclusion in Sanders-Brown Center on Aging Faculty Publications by an authorized administrator of UKnowledge. For more information, please contact UKnowledge@lsv.uky.edu. 


\section{Historical and Cross-Cultural Perspectives on Parkinson's Disease}

Digital Object Identifier (DOI)

https://doi.org/10.1515/jcim-2016-0065

\section{Notes/Citation Information}

Published in Journal of Complementary and Integrative Medicine, v. 15, issue 3, 20160065, p. 1-15.

(c) 2018 Walter de Gruyter GmbH, Berlin/Boston.

The copyright holder has granted the permission for posting the article here. 


\title{
Review
}

Lee Xenakis Blonder ${ }^{1}$

\section{Historical and cross-cultural perspectives on Parkinson's disease}

\author{
${ }^{1}$ Sanders- Brown Center on Aging and Departments of Behavioral Science, Neurology and Anthropology, University of Ken- \\ tucky, 101 Sanders-Brown Center on Aging, Lexington, KY 40536-0230, USA, E-mail: Ixblond@uky.edu
}

\begin{abstract}
:
Parkinson's disease (PD) is a common neurodegenerative disorder, affecting up to 10 million people worldwide according to the Parkinson's Disease Foundation. Epidemiological and genetic studies show a preponderance of idiopathic cases and a subset linked to genetic polymorphisms of a familial nature. Traditional Chinese medicine and Ayurveda recognized and treated the illness that Western Medicine terms PD millennia ago, and descriptions of Parkinson's symptomatology by Europeans date back 2000 years to the ancient Greek physician Galen. However, the Western nosological classification now referred to in English as "Parkinson's disease" and the description of symptoms that define it, are accredited to British physician James Parkinson, who in 1817 authored The Shaking Palsy. Later in the nineteenth century, French neurologist Jean-Martin Charcot re-labeled paralysis agitans "Parkinson's disease" and over a century of scientific research ensued. This review discusses European, North American, and Asian contributions to the understanding and treatment of PD from ancient times through the twentieth century.

Keywords: alternative medicine, ayurvedic medicine, history of medicine, Parkinson's disease, therapeutics, traditional Chinese medicine

DOI: 10.1515/jcim-2016-0065

Received: July 12, 2016; Accepted: March 22, 2018

\section{Introduction}

Parkinson's disease (PD) is a common neurodegenerative disorder, affecting up to 10 million people worldwide according to the Parkinson's Disease Foundation. The diagnosis of PD is based on the presence of clinical symptoms that have been refined over centuries and characterized across various cultures. At present, the International Parkinson and Movement Disorder Society clinical diagnostic criteria focus on motor abnormalities that include bradykinesia (slowness or poverty of movement) plus resting tremor or muscular rigidity [1]. In this article I delve broadly and deeply into the historical development of the Parkinson's diagnosis, and the Western and Eastern perspectives that have contributed to the understanding of PD. This article will also focus on treatment of PD across cultures and millennia and will discuss historic breakthroughs in the neurosciences that have improved and extended quality of life in PD patients.
\end{abstract}

\section{James Parkinson}

James Parkinson (1755-1824) was a physician practicing in Hoxton Square in the Shoreditch district of London in the late seventeenth, early eighteenth centuries [2]. Parkinson was an eclectic man, with interests that spanned medicine, politics, geology, and paleontology. In 1817, Parkinson published his now famous monograph entitled An Essay on the Shaking Palsy [[3](see Figure 1)].Parkinson referred to the malady as paralysis agitans (shaking palsy). While various accounts of symptoms that resemble that which we now term PD had been given before Parkinson's famous essay, he was one of the first to shine a spotlight on the symptoms of resting tremor, postural instability, and slowness of movement as characteristic of a single disease process. Parkinson based his postulate- that these symptoms form a distinct disease- on a series of six cases, some of which he merely observed in the street. In Parkinson's essay, he described the symptoms of paralysis agitans in detail and distinguished them from other maladies. For example, he noted that "resting" rather than what is now termed "intention" tremor, is a hallmark of the disease. The disease that Parkinson described and that is 
now named after him is idiopathic PD - as opposed to postencephalitic, post-traumatic, or PD secondary to manganese exposure [4]. Parkinson's astute observations are relevant to this day. In a biographical essay published in 1955, William McMenemey stated that Parkinson's "account of the disease is unsurpassed in the annals of medicine." So important is Parkinson's contribution to the understanding of this disease that his birthday - April 11th, was declared World Parkinson's Day in 1997 and organizations around the world use this day to raise awareness of the disease and to raise funds to support research, clinical, and educational efforts.

\section{E S S AY}

ON THE

\section{SHAKING PALSY.}

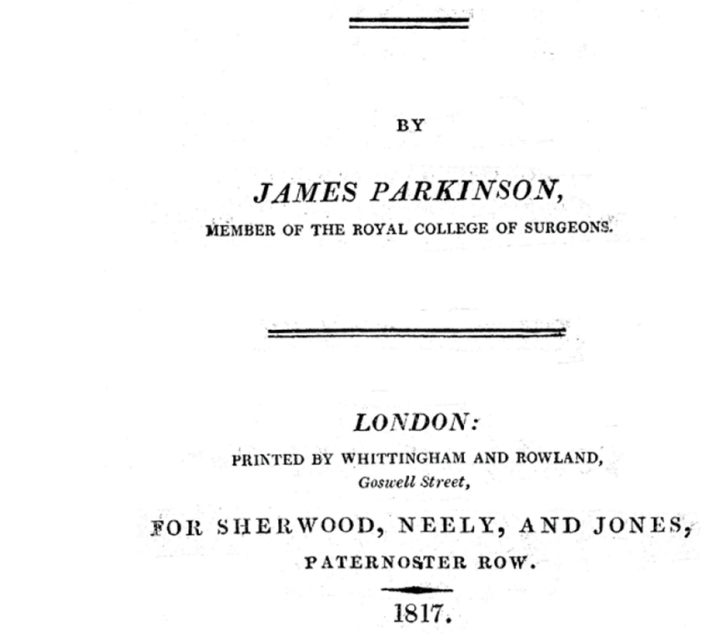

Figure 1: Cover of An Essay on the Shaking Palsy, published as a monograph in 1817 by Sherwood, Neely, and Jones, London. Source: Wellcome Library London.

Wellcome Collection. Photograph available under public license at this URL.

Parkinson's essay also provides broader insights into the history of Western medicine. In particular, Parkinson notes that the "shaking palsy" as he described it, "has not yet obtained a place in the classification of nosologists" (Parkinson, 1917, p. ii). Thus while he credits others including Galen (129-199), Sylvius de la Boë (1614-1672), Boissier de Sauvages de la Croix (1706-1767), and Gaubius (1705-1780) as having described some of the individual symptoms that constitute the disease, he himself classifies the symptoms, their timing and progression, as a single pathological process worthy of recognition in medical taxonomy. Parkinson went so far as to attempt to identify causality: "slow morbid change in the structure of the medulla, or its investing membranes, or theca, occasioned by simple inflammation, or rheumatic or scrophulous affection" (Parkinson, 1817, p. 52), but it is the recognition of the symptom cluster and the disease progression that proved to be prescient and that earned him lasting recognition in the annals of medicine. In 1884, some 60 years after the publication of his essay, French neurologist Jean-Martin Charcot (1825-1893) added rigidity to the symptomatology of paralysis agitans and renamed it "maladie de Parkinson" or PD [4, 5].

As originally noted by Parkinson, PD increases in frequency with advancing age and is most likely to develop in individuals over the age of 50. The average age of onset is about 60 and there is evidence that it continues to increase in prevalence until the ninth decade when the incidence begins to decline. In Parkinson's time, life expectancy was shorter than it is in many countries presently, and the population of aging individuals was considerably smaller. Hence the disease afflicted fewer people. Furthermore, as Parkinson pointed out, the disease is of long duration and years passes before the affliction is severe enough to cause death. However, in the twenty-first century, individual life expectancy in many counties is 80 years and beyond and the population of 
older individuals is increasing dramatically. In this context, the diagnosis of an age-associated slowly progressive neurodegenerative disease in ones fifties or sixties is very likely to impact quality of life and shorten the lifespan.

One important omission in Parkinson's description of the "shaking palsy" is dysfunction in cognition and emotion that we now recognize may accompany the disease process. This is apparent in the following definition of the disease given in "An Essay on the Shaking Palsy" and quoted by McMenemey [2]:

Involuntary tremulous motion, with lessened muscular power, in parts not in action and even when supported, with a propensity to bend the trunk forwards and to pass from a walking to a running pace:

the senses and the intellects being uninjured (p. 123)

The focus on PD as primarily motoric in nature has dominated the approach to research and treatment for centuries. In the last few decades however, it is increasingly recognized that neuropsychiatric symptoms, including depression, anxiety, and cognitive decline, contribute to disability and loss of quality of life [6].

In sum, James Parkinson formalized the disease as distinct from others, and this was reinforced by Charcot and subsequent generations of neurologists who call paralysis agitans or the shaking palsy "Parkinson's disease." However, the disease been documented world-wide for millennia. What understanding of the disease and its symptoms existed in Europe and on other continents prior to Parkinson?

\section{History of PD prior to James Parkinson}

\section{Europe}

Historical documents indicate that PD was recognized prior to the publication of James Parkinson's essay. As described previously, Parkinson himself referred to several of these accounts and integrated them into his formulation of paralysis agitans. One early account of importance that Parkinson did not reference was that of Hungarian physician Ferenc Pápai Páriz (1649-1716). According to an article by Daniel Bereczki [7], Páriz described all four signs of PD: tremor, hypokinesia, rigidity, and instability of gait- in a monograph published in Hungarian in 1690 entitled Pax corporis. Symptoms of what we now refer to as PD as quoted by Bereczki [7] were described in the third chapter of this book, "On tremulousness and paresis of the hand, leg, tongue, and other parts" (p. 291). Páriz also discussed the progressive nature of the disease and, in contrast to James Parkinson who located the disease in the spinal cord, suggested its locus in the "head" as emanating from the "substance of the brain" (Bereczki, 2010, p. 292). Páriz' account appears to be the most thorough description that was published prior to the "An Essay on the Shaking Palsy" by James Parkinson. To some extent, Páriz' depiction may have been more accurate. However, his text was not published in Latin and therefore was not widely read in Western Europe. Moreover, his chapter on tremulousness was only eight pages long, much shorter than Parkinson's monograph written more than a century later. It is only recently that Páriz' findings have come to light [7].

In the fifteenth century, Leonardo Da Vinci's writing described a condition resembling PD. Stern [8] provides a quote: "for you will see paralytics and those who are shivering and benumbed by cold move their trembling parts, such as their heads or hands without permission of the soul" (p. 12). Stern suggests that it is likely that DaVinci had seen the shaking palsy between 1489 and 1506, based on this observation having been noted on an anatomical drawing in the collection of the Queen at Windsor Castle. Prior to this, Greek physician Galen, writing between CE 129 and 199, described what we now term "festination" and other symptoms typical of PD [8]. As quoted by Stern [8], Galen describes a gait disorder as "a kind of paralysis which prevents people walking by mixing up the sides, exchanging left for right and right for left, failing to lift the foot and pulling it back instead, like those who walk up a steep incline" (p. 12). Galen may have also been the first to distinguish resting and action tremor, the former being characteristic of PD.

\section{China}

Traditional Chinese medicine (TCM) has evolved over several thousand years and is rooted in Taoism. It includes the use of botanical and medicinal preparations as well as practices such as acupuncture, tai chi, qi gong, and therapeutic massage to treat a variety of afflictions. Descriptions of a Parkinson's-like illness first appear in the Yellow Emperor's Internal Classic around 425-221 B.C. Volume 22 of the 24 volume classic describes symptoms of tremor and stiffness, crouching of the head and staring of the eyes, bending of the trunk with drooped shoulders, and tremor while walking [9]. Later, in AD 220-228 during Dynasty 6, a description of Parkinson-like 
festinating gate is given in the book Hua's Zhong Zang Classic. During the Jin dynasty, TCM expert Zhang Zihe (AD 1151-1231) gave a detailed account in his book Rumenshiqin of "wind shaking" in a man whose symptoms include tremor, stiffness, inability to perform motor activities, and loss of dexterity in addition to depressed affect. He also described a treatment termed Fangfeng Tongsheng Powder that included several Chinese botanicals $[9,10]$. During the sixteenth and seventeenth centuries, several practitioners of TCM described the symptoms of PD in considerable detail. Sun Yikui (1522-1619) of the Ming Dynasty named the disease Chanzheng or "tremor syndrome in the elderly [10]." He developed a treatment to eliminate liver pathogens termed CuiganWan that consisted of a variety of plant-based derivatives [10]. Pharmacologic studies of these compounds, still in use today by practitioners of TCM, show that they have anticholinergic, antioxidant, and free radical scavenging effects [9]. The herb gastrodia, used in TCM preparations, increases dopamine levels in an animal model and may possess neuroprotective effects [9].

In addition to herbal medicine, TCM practices such as acupuncture and tai chi have proven beneficial in PD. The application of acupuncture to alleviate Parkinson-like symptoms dates back centuries. An entry recorded by Zhang Zhongjing (152-219 AD) in the "Treatise on Cold Damage and Miscellaneous Diseases" recommends acupuncture for a disease he named Fujue, a PD-like syndrome [10]. Acupuncture points are selected in accordance with TCM theory. In a recent meta-analysis based on 19 Chinese and Korean clinical trials, acupuncture was found to be effective in improving PD motor function, particularly when used in conjunction with conventional pharmaceutical treatment [11]. Based on preclinical studies in mice, the authors suggest that acupuncture may prevent cell death in the pars compacta region of the substantia nigra. They recommend targeting specific acupuncture points to achieve this effect. Studies in mice also indicate that acupuncture promotes clearance of alpha synuclein, a protein that aggregates in PD brains [12].

Like acupuncture, the ancient Chinese martial art, tai chi, is also used to alleviate Parkinsonian symptoms. Tai Chi combines slow and graceful body movements and deep breathing. It has been particularly well-studied in PD recently as a practice that improves postural stability and balance and reduces the incidence of falls $[13,14]$. In TCM, yin and yang must be balanced to support energy flow ( $q i)$ and health. When these forces are not in balance, $q i$ stagnation can occur. Acupuncture and Tai Chi may exert positive effects on PD patients by harmonizing the yin and yang aspects of $q i$. In scientific medicine, these concepts may be understood as analogous to metabolism, immunity, and homeostatis [15]. More specifically, studies designed to uncover the neurobiological basis of TCM "mind-body" practices suggest that they may exert their healing effects in PD by reducing inflammation and increasing blood flow, electrical signaling, and neurotransmitter bioavailability [16-18]. Recently a group of Chinese neurologists published consensus guidelines for the integrative treatment of PD in China [19]. They recommended specific and/or personalized TCM treatments (depending upon the expertise of the practitioner), in conjunction with Western pharmaceutical and surgical interventions.

\section{India}

Perhaps the earliest written description of an illness that resembles what Western medicine terms PD is found in ancient Ayurvedic texts. Ayurveda, translated as "the science of life," is a medical system practiced in India and developed by the Vedic culture over 5000 years ago [20]. The major text, Charaka Samhita, dates to about 2400 BP. Descriptions written in Sanskrit of a disease that includes tremor, drooling, difficulty with movement, and depression appear in this ancient Ayurvedic text and in subsequent texts written in between the fifth and twelfth centuries [21,22]. This disease was named kampavata in fifteenth century Ayurvedic literature [22]. Vata is one of three doshas or bodily humors that make up one's constitution. Vata governs movements and sensations. Kampa means tremor. In Ayurvedic medicine, the disease was treated with a preparation termed Masabaladi Pacana that was derived from Mucuna pruriens [21,23]. This plant is a member of the Leguminosae family which is indigenous to India. It contains $4 \%-6 \%$ L-3, 4-dihydroxyphenylalanine or levodopa (L-dopa) and may also have dopamine agonist activity [24, 25]. Research in an animal model suggests that Mucuna pruriens may be more effective than synthetic L-Dopa in treating Parkinson's symptoms [26]. A small clinical trial in Parkinson patients conducted in 2004 showed that Mucuna pruriens powder produced a more rapid onset and longer duration of "on" time without increases in dyskinesias when compared with standard L-dopa/carbidopa [27]. Aruyvedic physicians also gave additional neuroactive botanicals in conjunction with Mucuna pruriens, including ashwagandha (Withania somnifera), a botanical known to reduce anxiety, and bala (Sida cordifolia), a medicinal plant that contains ephedrine, a norepinephrine agonist. These herbs are currently available as dietary supplements and can be purchased on the internet. Thus millennia prior to Nobel Laureate Arvid Carlsson's discovery in the 1950s that dopamine is a neurotransmitter involved in the control of movement, or Birkmayer and Hornykiewicz' 1961 trial demonstrating "miraculous" results using L-Dopa as a therapeutic agent in PD [28], Ayurvedic practitioners were giving kampavata patients L-dopa.

Another tradition rooted in the Vedic philosophy of ancient India that has benefitted PD patients is yoga. Yoga originated as a spiritual practice that combines bodily poses with meditation and breathing. The West 
has adopted yoga as a "mind-body" modality and recent studies suggest that it may improve motor function and quality of life in PD patients [29,30]. From a scientific perspective, yoga is not as well studied in PD as acupuncture and tai chi. However, its mechanisms of action may be similar. In particular, evidence suggests that yoga has neuroprotective effects such as preserving gray matter volume, increasing regional brain functional connectivity, and reducing inflammation [31]. Yoga represents another ancient Eastern practice that is used in conjunction with medicinal treatments to benefit PD patients.

\section{Nineteenth century European developments in the understanding and treatment of PD}

Following the publication of "An Essay on the Shaking Palsy", additional accounts of PD appeared in the literature. Wilhelm von Humboldt (1767-1835), German scholar, statesman, and founder of the Berlin University, gave a lay account of his personal experience with PD in a lengthy correspondence with friend Charlotte Diede (1769-1846). In these letters, published after the Diede's death, von Humboldt described with exceptional precision the symptoms of PD [32]. These included trembling, difficulty with fine motor movements, micrographia, and slowness of movement. He attributed these symptoms to advancing age and the death of his wife. Von Humboldt's brother, renowned naturalist Alexander von Humboldt, wrote on the occasion of Wilhelm's death, that his brother had a curved posture, tremor and that his death was caused by pneumonia. One year prior, von Humboldt's daughters reported that their father looked very thin, exhibited slowness of movement, tremor, curved posture and what we would now term "aprosodia" or monotone speech. Von Humboldt's curved posture is shown in a statuette of him by Friedrich Drake dated 1834, one year prior to von Humboldt's death [32].

Jean-Martin Charcot (1825-1893; Figure 2), widely considered the "father" of neurology, made notable contributions to our understanding of PD.

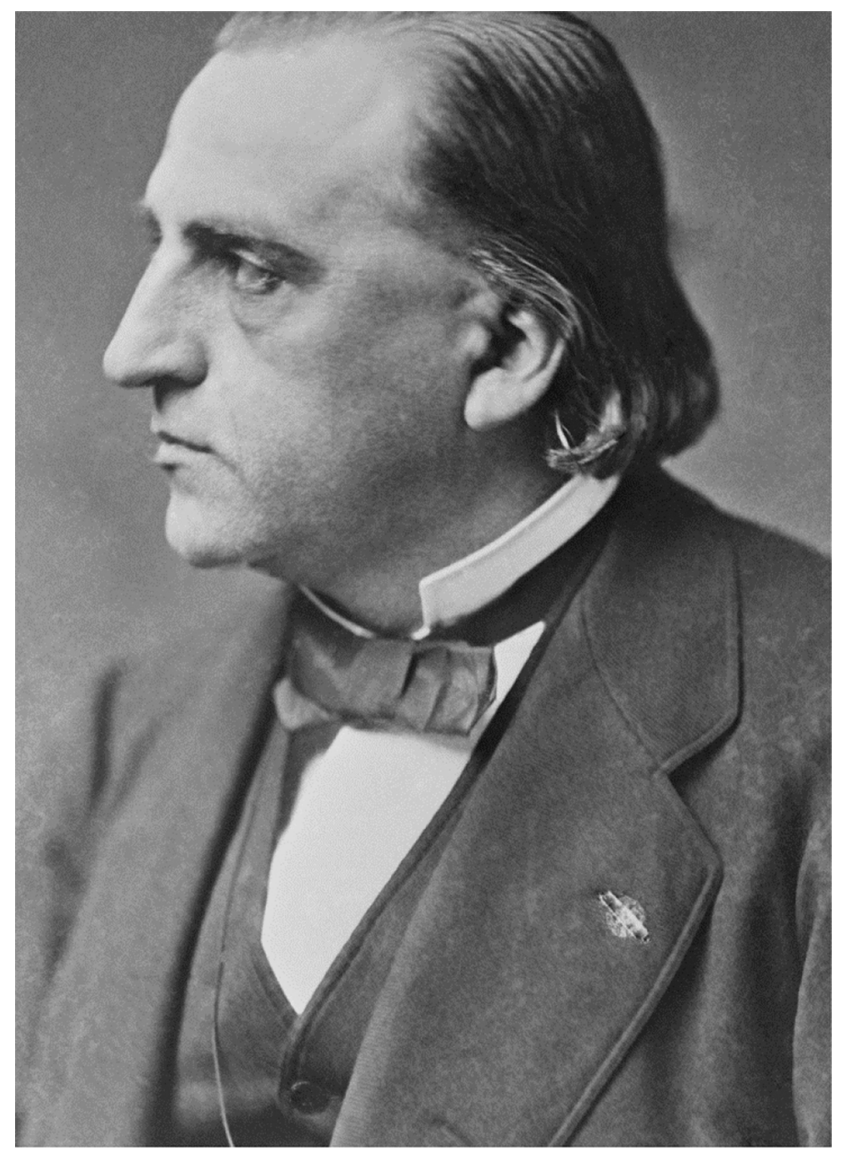

Figure 2: Jean Marie Charcot (1825-1893); Source: Wellcome Library London. Wellcome Collection. Photograph available under public licence at this URL.

As described previously, Charcot renamed paralysis agitans "maladie de Parkinson." As a neurologist and academician at the famous Salpêtrière Hospital in Paris, France, Charcot established the first neurology clinic 
in Europe and saw hundreds of patients over the three plus decades he practiced there. Charcot had diverse interests, spanning psychiatry and neurology. He conducted extensive studies of tremor and contrasted typical and atypical variants of PD. The atypical presentations Charcot described would likely be termed Parkinsonplus syndromes currently [(corticobasal degeneration, progressive supranuclear palsy, and multiple system atrophy)[33]]. Charcot also developed treatments for PD. These treatments largely targeted tremor and consisted of preparations that have anticholinergic effects, such as belladonna and hyoscyamine, tropane alkaloids found in plants belonging to the Solanaceae or nightshade family. He also treated PD patients with ergot alkaloids. Ergot products are derived from a fungus present in rye. These compounds induce vasoconstriction and act as dopamine, serotonin, and norepinephrine receptor agonists. Charcot observed that Parkinson patients obtained some relief from resting tremor after carriage or horseback rides and postulated that the vibration was responsible for the effect. He designed an electrically powered "shaking chair" that he used in treatment [33]. Later, his student Gilles de la Tourette developed a shaking helmet that could be more easily transported. Neither of these treatments gained widespread use.

Another important figure in the history of PD was British neurologist Sir William R. Gowers (1845-1915; Figure 3). Gowers devoted an entire chapter to paralysis agitans in his famous textbook entitled "Manual of Diseases of the Nervous System" [34].

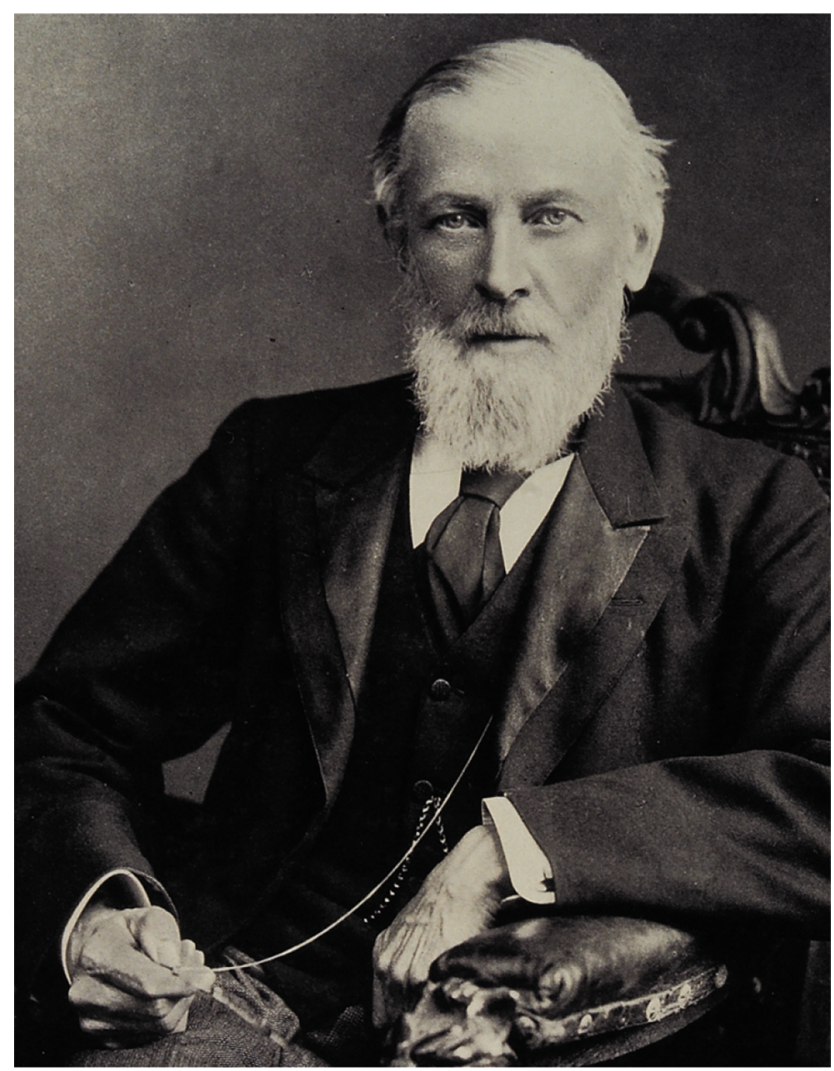

Figure 3: Sir William R. Gowers (1845-1915). Source Wellcome Library London.

Wellcome Collection. Sir William Richard Gowers. Photogravure after Maull and Fox. Photograph available under public license at this URL.

In 1945, Macdonald Critchley stated that Gowers was "probably the greatest clinical neurologist of all time" [35]. Many of Gowers' observations remain accurate to this day. For instance, he noted that the disease is more frequent in men than in women, that it usually begins after age 40 that heredity can be traced in about $15 \%$ of cases, and that it has a chronic and progressive course. He considered various precipitating factors and described the symptoms of PD in great detail, including the observation that the "facial muscles seem to be unable to respond to the varying changes of emotion." He astutely observed that "mental depression" may accompany the disease and expressed uncertainty as to whether depression is a result of the physical ailment. This foreshadowed the prevailing view that Parkinsonian depression may stem from abnormalities in neurotransmitters as well as fronto-subcortical connections that regulate mood [6]. Gowers also notes that loss of memory accompanied by delusions is sometimes present in late stages. He describes the disease as involving the central nervous system, and asks rhetorically whether the motor cortex is the seat of the disease. Very little information on the neuropathology of PD was known at the time or is presented in Gowers' text. He describes treatments for tremor that were in use in Europe, including morphine, hyoscyamin, static and voltaic electricity, 
opium, Indian hemp, and arsenic. Indian hemp is a cannabinoid that was imported from Kolkata to the British Isles in the nineteenth century and used by Gowers in the treatment of PD. That plus opium combined with arsenic was his preferred remedy.

\section{Neuropathological discoveries}

Identification of the neuropathology of PD commenced in the late nineteenth century when Edouard Brissaud (1852-1909), a student of Charcot and his successor at the Salpêtrière Hospital in Paris, suggested that the substantia nigra may be involved in PD based on a prior case report. This idea did not gain traction for decades while various other theories emerged regarding the pathogenesis of the disease [4].

In 1919 the Russian pathologist Konstantin Tretiakoff (1892-1958) produced a doctoral dissertation l'Anatomie pathologique du Locus Niger in which he examined the substantia nigra of 54 brains including six with paralysis agitans. He noted marked loss of pigmented neurons in the substantia nigra associated with PD in addition to other pathological features including inclusion bodies, which he named "corps de Lewy" after Friedrich Lewy who had described them 7 years previously [36]. Tretiakoff's thesis, that lesions in the substantia nigra were pathonomic of PD, was not widely accepted at the time, despite the fact that it may have been one of the most important neuropathological findings of the twentieth century [36]. In 1925 French Neurologist Jean Llermitte conceded that all cases of PD studied contained lesions of the substantia nigra as described by Tretiakoff. Work by Charles Foix and Cecile and Oskar Vogt conducted in the 1920s and 1930s contributed to current understanding of the role of the basal ganglia and substantia nigra in PD. Two decades later, their daughter Marthe Vogt, conducted landmark studies of the distribution of epinephrine and norepinephrine in the brain [37]. In 1938, Rolf Hassler, working in the laboratory of the Vogts', completed a thorough examination of the substantia nigra in 9 cases of paralysis agitans and 11 cases of post-encephaletic PD. He concluded that lesions of the substantia nigra were a hallmark of the disease [38]. This was later confirmed by Bertler and Rosengren in 1959 who used histofluorescence to demonstrate severe nigrostriatal loss in PD [36]. In 1960, Ehringer and Hornykiewicz measured dopamine in the autopsied brains of patients with Huntington's disease, PD, and other extrapyramidal disorders and found that only the Parkinson brains had severe dopamine cell loss in the caudate and putamen [39]. Subsequent neuropathological findings include the discovery in 1997 that alpha-synuclein, a presynaptic protein present in brain tissue, is the main component of Lewy Bodies in idiopathic PD and in dementia with Lewy bodies [40]. PD is currently classified as an alpha-synucleinopathy together with Lewy Body dementia and multiple system atrophy. Braak et al. [41] suggested that motor and non-motor symptoms in idiopathic PD are related to a larger pathologic process involving a progressive caudal to rostral aggregation of alpha-synuclein in select nerve cells, although this is somewhat controversial [42, 43].

\section{Discovery of L-DOPA, dopamine and advances in the treatment of PD}

As this review illustrates, practitioners of Ayurveda, TCM, and European neurology were using botanical preparations to treat Parkinson symptomatology centuries ago. These plant-based medicinals included but were not limited to gastrodia, Mucuna pruriens, ashwagandha, bala, belladonna, hyoscyamin, and cannabis. Beginning in the early twentieth century, physicians and scientists operating in both the clinic and the laboratory uncovered important information regarding the neurotransmitters and neural pathways implicated in PD, the chemical make-up and mechanism of action of traditional preparations, and treatment approaches based on compounds for which pharmaceutical companies subsequently obtained patents.

The isolation of L-DOPA, its subsequent synthesis in the laboratory, and its formulation as a treatment for Parkinson's motor symptomatology are considered landmarks in the history of neurology. L-DOPA is produced in the body from the amino acid L-tyrosine by the enzyme tyrosine hydroxylase. The neurotransmitter dopamine is formed via the decarboxylation of L-DOPA. Dopamine is critical to motor, cognitive, and emotional brain functions. This has become apparent through decades of basic science, clinical, and neuroimaging research on PD.

D, L-DOPA (the form containing left and right-handed enantiomers) was first synthesized in 1911 by Polish chemist Kazimierz (Casimir) Funk (1884-1967). Interestingly, Funk is best known for his discovery of vitamins. In 1913, Marcus Guggenheim (1885-1970), a Swiss-German chemist working for Hoffmann-LaRoche in Basel, Switzerland, isolated the pure enantiomer (mirror image molecule) L-Dopa from the legume Vicia faba [28]. L-DOPA is the biologically active form and the form subsequently synthesized for use in treating PD. In 1937, Damodaran and Ramaswamy[25] isolated L-DOPA from Mucuna pruriens. The seeds of this plant contain greater amounts than Vicia faba and are the source used in Ayurvedic treatments of kampavata. 
In 1938, more than two decades after the isolation of L-DOPA by Marcus Guggenheim, Peter Holtz discovered the enzyme DOPA decarboxylase which converts L-DOPA to the biologically active amine dopamine, which at that time was referred to as 3-hydroxytyramine[44]. In 1952 Sir Henry Dale, Nobel Laureate and British pharmacologist, renamed 3-hydroxytyramine dopamine to better signify its relationship to L-DOPA [45]. However, it was not until the seminal paper of Kathleen Montagu, published in "Nature" in 1957, that dopamine was known to exist in the brain [46]. Other scientists who conducted important studies of dopamine in the 1950s include Wilhelm Raab [47], Hans Weil-Malherbe [48], Peter Holtz [49], Åke Bertler and Evald Rosengren [50], Oleh Hornykiewicz [51], and Isamu Sano [52]. Among the many researchers active in this field in the 1950s, the experimental findings of Arvid Carlsson (1923-), Swedish physician and neurophysiologist, have been recognized as ground-breaking (see Figure 4).

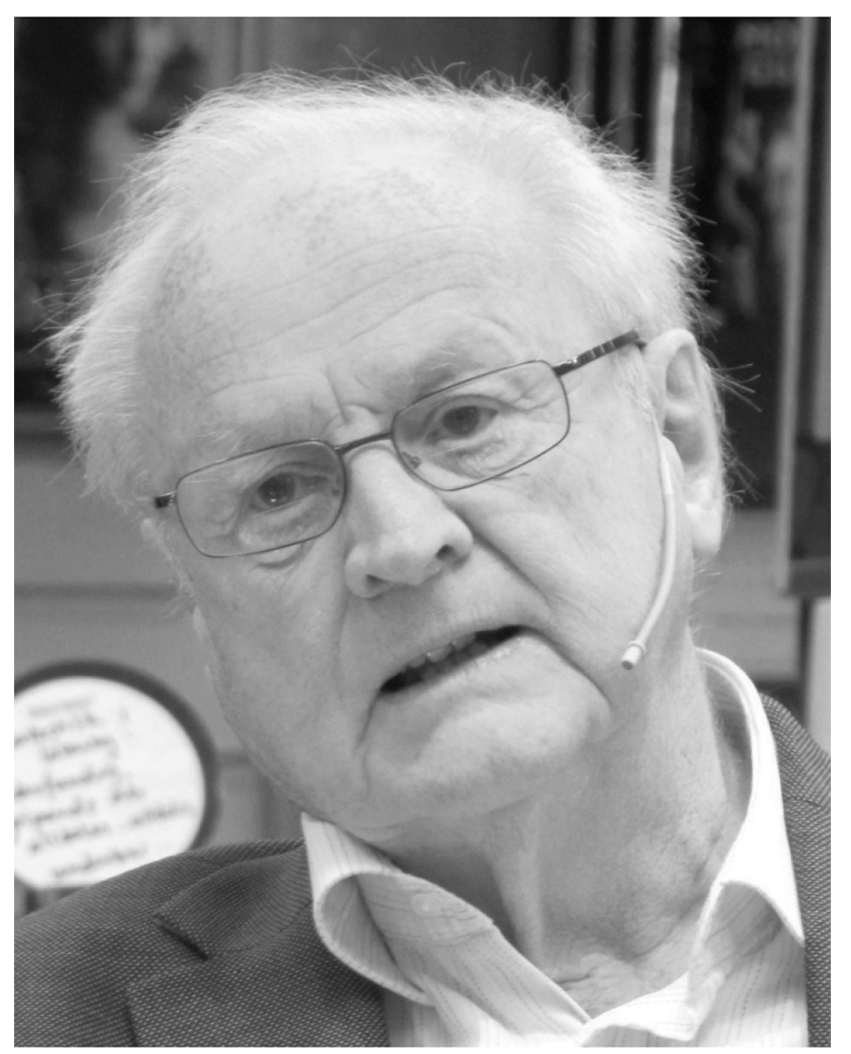

Figure 4: Arvid Carlsson (1923- ) giving a lecture at the 2011 Göteborg Science Festival; Source Wikipedia; Creative Commons.

Licensed under Creative Commons Share-Alike 3.0 Unported license.

Carlsson was the first to demonstrate that dopamine functions as a neurotransmitter in the brain. Prior to his work, dopamine was thought to have limited physiological activity and its major role as a precursor to norepinephrine. Carlsson and his collaborators showed that L-DOPA, a dopamine precursor capable of crossing the blood-brain barrier, has the ability to reverse symptoms induced by reserpine, a drug that depletes norepinephrine and dopamine in the brain, lowers blood pressure, and can produce Parkinson-like symptoms in laboratory animals $[53,54]$. Dopamine does not cross the blood brain barrier and hence the precursor must be used in targeting the brain. Carlsson's extensive research on L-DOPA and dopamine lead him to speculate that dopamine depletion lead to PD and that treatment with L-DOPA would restore dopamine and alleviate symptoms [54,55]. At first Carlsson's findings were met with skepticism, but Carlsson observed that by 1965 a "paradigm shift" had occurred, with major researchers in the field acknowledging the important role of catecholamines (epinephrine, norepinephrine, and dopamine) in the peripheral and central nervous systems [55, 56]. In 2000, Carlsson was awarded the Nobel Prize in Physiology or Medicine for his pioneering work.

Carlsson's contemporaries, particularly Japanese neurologist Isamu Sano (1924-1975), Polish physician and research scientist Oleh Hornykiewicz (1926-), Canadian neurologist André Barbeau (1931-1986), and Greek American neurologist George Cotzias (1918-1977) made ground-breaking discoveries on the neuropharmacology and clinical significance of L-DOPA and dopamine. In 1959, Isamu Sano presented a paper at the International Catecholamine Symposium on the distribution of dopamine in the human brain [52]. One year later, Sano gave a lecture in Tokyo describing a study he conducted in which he found decreased levels of dopamine in the brain of a deceased Parkinson patient. That same year, Sano showed a reduction of rigidity in a Parkinson patient who received intravenous DL-DOPA $[55,57]$. Sano's work was originally published in Japanese 
and was not widely known at the time. Moreover, he himself expressed skepticism that the results had therapeutic implications. Years later, in 2000, his studies were translated into English and published in the journal "Parkinsonism and Related Disorder" [58].

Also in 1959, Carlsson's doctoral students Åke Bertler and Evald Rosengren [50] found dopamine localized in the basal ganglia of the dog. This inspired Hornykiewicz and his postdoctoral fellow Herbert Ehringer to measure dopamine in the brains of 6 Parkinson patients, 17 neurologically healthy adult controls, and 8 additional individuals with neurodegenerative diseases involving the basal ganglia [39]. Findings indicated that only the Parkinson patients had severe loss of dopamine in the caudate and putamen. Following confirmation that PD was associated with depletion of dopamine in the basal ganglia, Hornykiewicz teamed up with Walter Birkmayer (1910-1996), an Austrian neurologist who directed the neurological ward at "The Home for the Aged" in Vienna. Birkmayer had access to many patients and together he and Hornykiewicz conducted the first trial of L-DOPA, administering it intravenously to advanced Parkinson patients. Patients who were formerly bed-ridden were able to walk across the room, run, and jump and their speech became audible and clearly articulated [59]. The results were hailed as miraculous and eventually resulted in the development of levodopa as a universal treatment for PD. Around the same time (1961), André Barbeau and colleagues published a study showing reduced urinary excretion of dopamine in Parkinson patients compared to controls [60]. Subsequently, Barbeau, Theodore Sourkes, and Gerald Murray administered oral L-Dopa to PD patients and observed transient improvement in motor function [61]. In 1963, Hornykiewicz found reductions of dopamine in the substantia nigra in PD brains, leading him to speculate that the loss of dopamine in the basal ganglia might be due to nigral deficiencies [62].

Throughout the 1960s, several notable neuroscientists disputed the importance of Hornykiewicz' findings and expressed skepticism that L-DOPA would serve as a viable therapeutic agent in the treatment of PD [63]. This changed dramatically in subsequent years. In fact, the contributions of Hornykiewicz were eventually considered of such significance that more than 250 neuroscientists from around the world published an open letter to the Nobel Prize in Medicine committee in the April 2001 issue of "Parkinsonism and Related Disorders", stating that Hornykiewicz should have been included among the Year 2000 Nobel Prize recipients- the year that Arvid Carlsson, Paul Greengard, and Eric Kandel shared the Nobel Prize in Medicine or Physiology for their work in signal transduction in the nervous system. The Nobel Foundation does not reverse or alter decisionshence Hornykiewicz did not obtained this recognition. However, he has received numerous other prestigious scientific awards including the Wolf Prize in Medicine (1979) and the Warren Alpert Foundation Prize (2014; Figure 5).

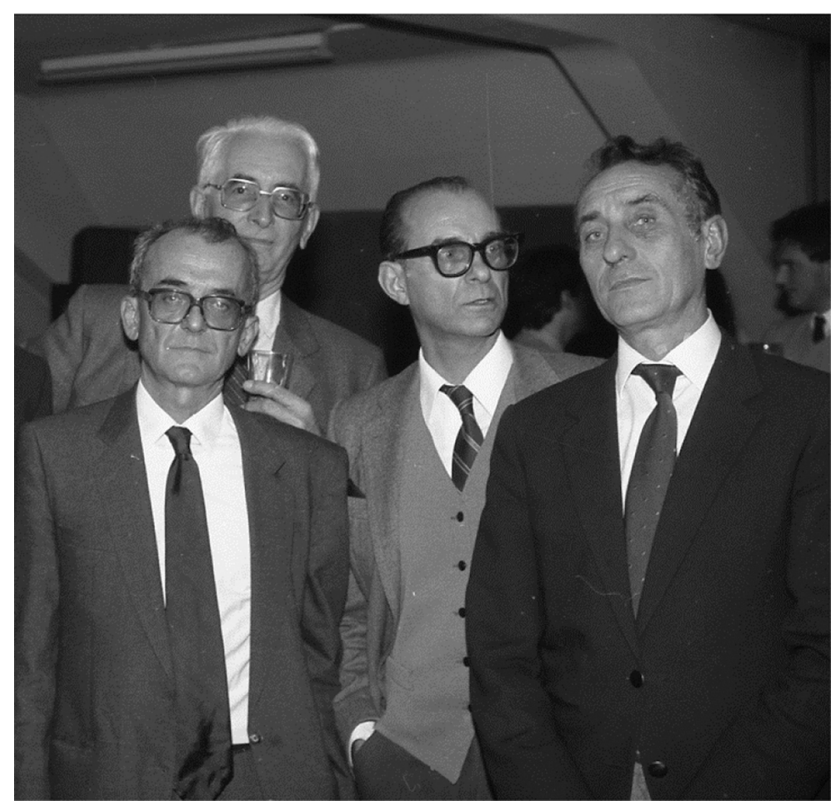

Figure 5: Georg Hertting, Hans Klupp, Oleh Hornykiewicz und Walter Kobinger; Source: Wikimedia Commons. Fotoarchiv Benutzer:Coranton; Author Renate Heldt. Public Domain.

One important impediment to the use of L-DOPA as a treatment for PD was that, administered intravenously in low doses, it was short-acting and therefore impractical. Moreover, prior studies including a self-test by Guggenheim in 1913 demonstrated intolerable side effects such as nausea and vomiting [45]. The future of LDOPA as a treatment for PD looked bleak, until the late 1960s when George Cotzias published a seminal paper in the "New England Journal of Medicine" that revolutionized the treatment of PD [64, 65]. George Cotzias was born in Crete to prominent parents and emigrated to the United States in 1941 when German troops invaded 
Athens. He eventually graduated from Harvard Medical School and completed his residency in Neurology at Massachusetts General Hospital. While working at Brookhaven National Laboratory on Long Island, New York, Cotzias and his colleagues developed an oral treatment method that slowly increased the dose of L-DOPA over a period of weeks to much higher amounts than had been previously given. Cotzias was able to do this in part because he had access to an inpatient facility and was able to monitor and administer L-DOPA in a very gradual and systematic manner [45]. His original intent was to restore neuromelanin concentrations in the brain by administering L-DOPA, a melanin precursor [64]. Although he was not successful in this, he did find that progressively increasing the dose and consistently maintaining a high dose (4-18 grams per day) eliminated nausea and vomiting and achieved remission of Parkinson's symptoms [65]. Cotzias also found that co-administration of L-DOPA and a peripheral dopa decarboxylase inhibitor permitted lower therapeutic doses of L-DOPA to be given since more drugs crossed the blood-brain barrier to be converted to dopamine in the brain. This eradicated side effects in some patients. The combination of carbidopa, a dopa decarboxylase inhibitor in the periphery, and levodopa is still in use today. Cotzias' later work also lead to the development of dopamine agonists as a treatment for PD [56]. Cotzias contributed immensely to the treatment of PD and was referred to by collaborator Lily Tang as the "Zorba of Science" [66]. His papers were published in the most prestigious journals and he received a number of awards, including the Albert Lasker Award for Clinical Medical Research (Figure 6).

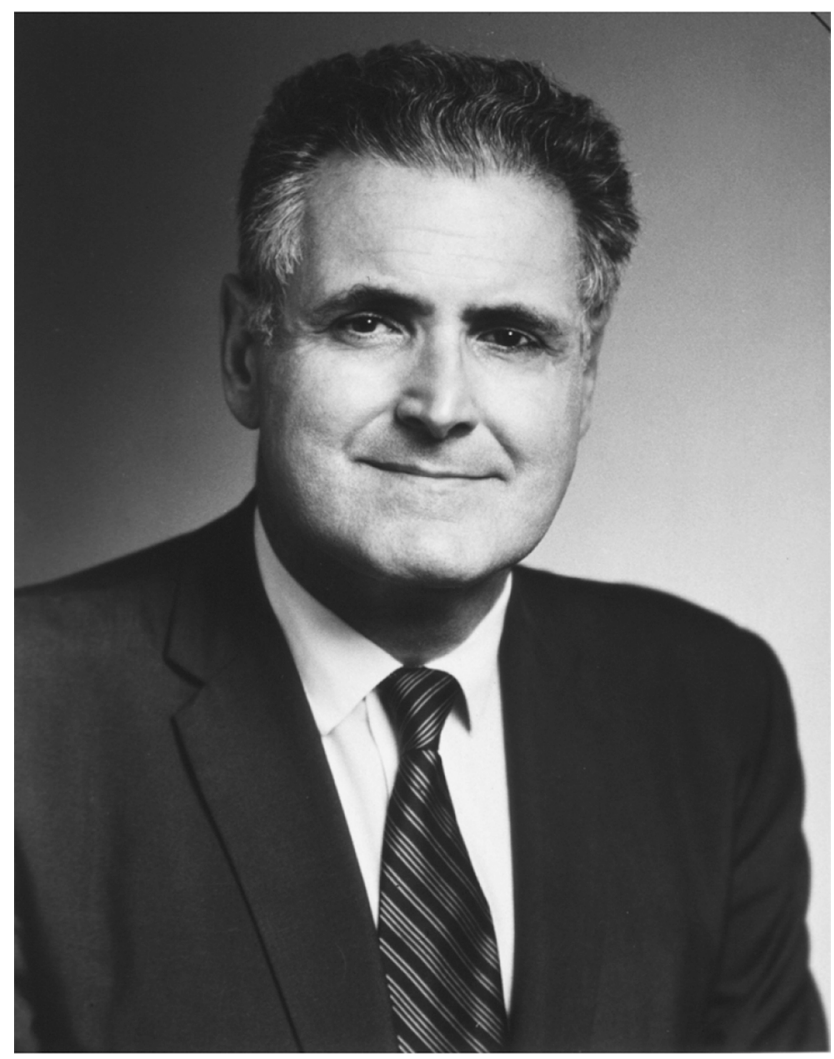

Figure 6: George Cotzias (1918-1977); Source: U.S. National Library of Medicine Digital Collections. Public Domain.

Unfortunately, Cotzias developed lung cancer and died in 1977 at the age of 58 at Memorial Sloan Kettering hospital, his then place of employment. Prominent members of the local and international communities attended his memorial service, including Laurence S. Rockefeller, the North American Arch Bishop of the Greek Orthodox Church, and several Greek ambassadors. In recognition of his accomplishments, the Greek government issued a commemorative stamp [56].

Cotzias' studies were open label, meaning that patients and clinicians alike knew what treatment was being given. In 1969, Melvin Yahr (1917-2004) and colleagues conducted a prospective, double-blind, placebo controlled clinical trial [67]. Yahr was born in New York City and attended New York University, earning both his bachelor's and medical degrees there. He received his neurology training at Montefiore Hospital in the Bronx and later joined the faculty at the Neurological Institute of Columbia University. He was the first scientific director of Columbia's Parkinson's Disease Foundation, supported by philanthropic donations (Figure 7). 


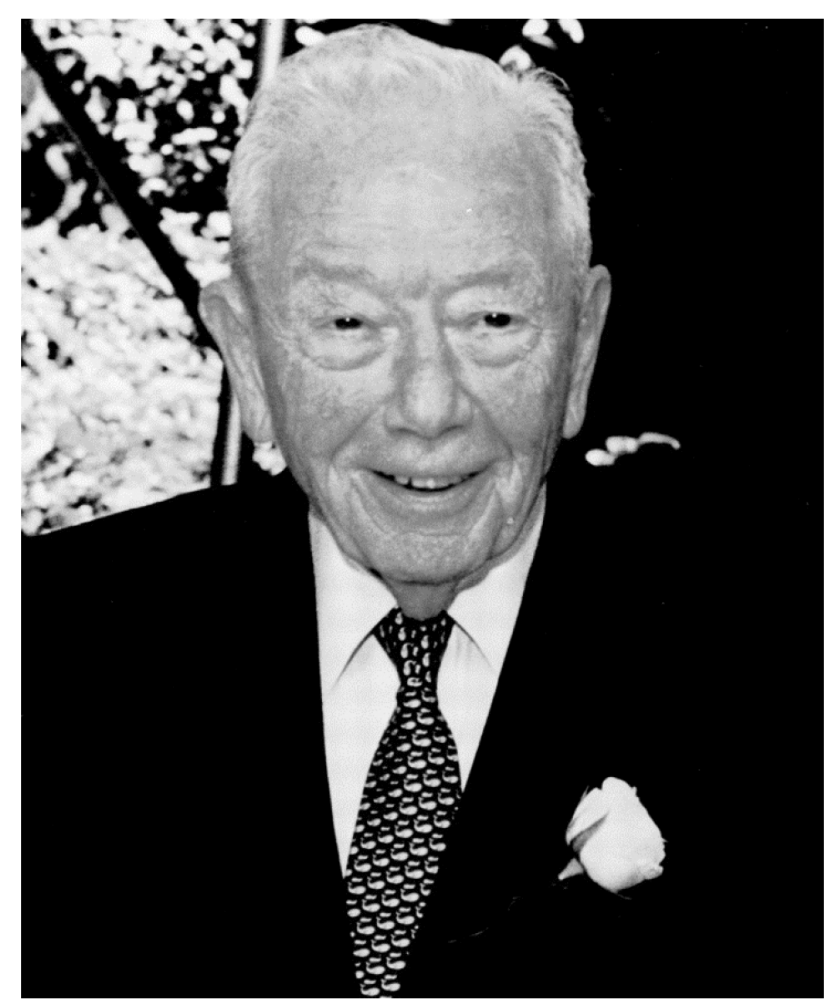

Figure 7: Melvin Yahr (1917-2004).

This photograph originally appeared in the In Memoriam essay by C. Warren Olanow published in Neurology on June 8th, 2004 [volume 62(11):1932-1933]. Reproduced with permission from Wolters Kluwer Health, Inc.

Yahr was familiar with the work of Carllson, Hornykiewicz, and Cotzias and sought additional confirmation of the efficacy of L-DOPA in treating the motor symptoms of PD. Of the 60 Parkinson patients enrolled in the 1969 study, 81\% showed clinical improvement in motor symptomatology, including tremor, rigidity, and bradykinesia. Chronic treatment was associated with dyskinesias and this problem persists to this day, although side effects such as nausea and vomiting have been eliminated using dopa decarboxylase inhibitors [56]. Following the study by Yahr et al, the use of L-DOPA as a treatment for PD was widely adopted and medications that contained L-DOPA plus a dopa decarboxylase inhibitor received FDA approval. The most widely used of these is marketed under the name of Sinemet囚.

Melvin Yahr is perhaps best recognized for his work with his clinical fellow, Margaret Hoehn (1930-2005; Figure 8). 


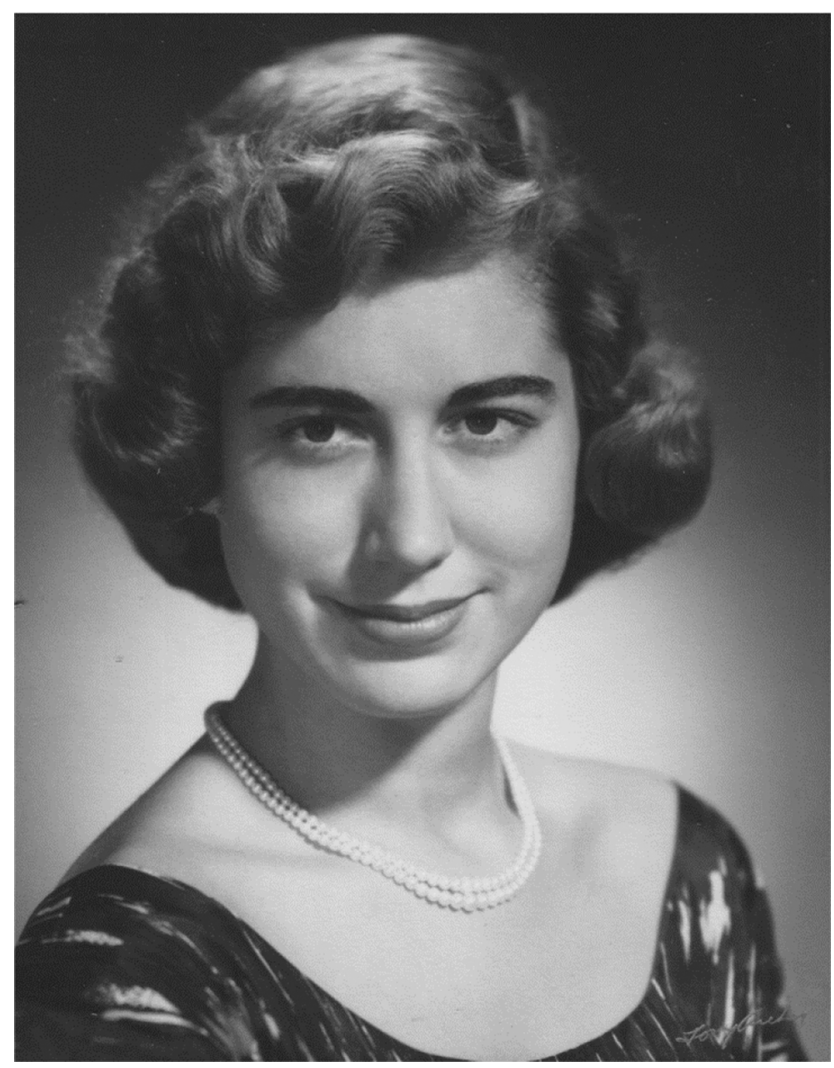

Figure 8: Margaret Hoehn (1930-2005).

Reproduced with permission from the Denver Post.

Hoehn and Yahr published the widely known "Hoehn and Yahr scale" in 1967, the same year that Cotzias published his first important study of L-DOPA in the treatment of PD. Margaret Hoehn received her Bachelor's and medical degrees from the University of Saskatchewan. After training in Neurology in Vancouver, Boston, and London she joined Melvin Yahr's Movement Disorder Group at Columbia University as a Clinical Fellow. In their now classic paper, Hoehn and Yahr recorded data on 802 Parkinson patients seen at the Vanderbilt Clinic of the Columbia-Presbyterian Medical Center University between 1949 and 1964 [68]. Of these, 672 patients were determined to have idiopathic PD. During the period from 1963 to 1964, 263 Parkinson patients were examined in the Neurology Clinic, and these examinations provided more detailed data. Hoehn and Yahr reported demographic information, age of onset, clinical presentation, duration of illness, clinical progression, and mortality rate [69]. The scale they developed lists detailed criteria to classify disease progression into five stages. It provides precise staging criteria and was subsequently modified to include stages 1.5 and 2.5 . The modified Hoehn and Yahr scale is universally used to this day to stage Parkinson patients.

The scientific and clinical discoveries that occurred during the 1950s and 1960s rapidly altered the treatment of PD. At the same time that Cotzias and others were experimenting with L-DOPA as a treatment for the motor symptoms of PD, Hoehn and Yahr published their PD rating scale that would later be used in clinics worldwide and by thousands of researchers. By the late 1960s, Cotzias' treatment had inspired scientists at Roche and Merck to develop and patent formulas based on the combination of L-DOPA and a dopa decarboxylase inhibitor. Victor Lotti at Merck was involved in the development of carbidopa, the peripheral dopa decarboxylase inhibitor used in Sinemet ${ }^{\circledR}$ (Latin: sin èmetos, without emesis or vomiting), which was approved in May of 1975 . Sinemet ${ }^{\circledR}$ contains L-DOPA, which crosses the blood brain barrier and is converted to dopamine by the enzyme DOPA decarboxylase, activating D2 receptors. Carbidopa does not cross the blood brain barrier. Instead, it inhibits DOPA decarboxylase in peripheral tissue, thus preventing L-DOPA side effects of nausea and vomiting. Moreover, the addition of carbidopa increases the half-life of L-DOPA as well as the amount of L-DOPA that crosses the blood brain barrier, permitting a downward titration in dose. In 1991, Dupont and Merck joined forces to release a sustained release formulation of Sinemet $\left(\right.$ (Sinemet $\left.{ }^{\circledR} C R\right)$. Currently there are multiple forms of Sinemet ${ }^{\circledR}$ on the market and there have been numerous regulatory revisions of the product since it was first introduced in 1975. The market for Sinemet ${ }^{\circledR}$ is in the billions of US dollars with over 5 million Parkinson patients world-wide and the numbers expecting to surge as populations expand and age. However, based on several factors including the introduction of generics and competitive treatments, Sinemet巴's sales have dropped in recent years. In 2010-2011 there was a world-wide shortage of Sinemet巴 due to changes made by Merck in the manufacturing of the drug. In addition, patients' reported that the new formula, once available, 
was less long-lasting and more difficult to cut in half due to lack of scoring, despite formal clinical instructions supporting the use of half-tablets. Taken together, the shortage, as well as changes in the formulation instituted by the new manufacturer Mylan, proved to be very distressing to patients, and the National Parkinson Foundation along with additional stakeholders spoke out to advocate for better practices and a more patient-centered approach in the future.

While there have been many advances in the treatment of PD since the discovery and introduction of levodopa in the early to mid-1970s, levodopa/carbidopa therapy is considered revolutionary [45]. The discovery of levodopa as a replacement therapy for a neurotransmitter involved in a neurodegenerative disease has served as a model in drug development. While other symptomatic treatments have been introduced since the early 1970s, most notably dopamine agonists, levodopa remains the mainstay of treatment. Recent evidence from the ELL-DOPA trial suggests that levodopa might be also neuroprotective- and not simply a symptomatic dopamine replacement therapy, but that will require further substantiation [70].

\section{Conclusions}

In this review I have provided a historical perspective on the events that culminated in PD as a definitive diagnosis in Western Medical nosology. I have also reviewed historical data on non-Western knowledge and treatment of what we in the English speaking world refer to as PD. This literature shows that TCM and Ayurveda described the symptoms of PD centuries and millennia ago. Many of the treatments that have been utilized in these systems are plant-based medicinals that we now know, due to the scientific discoveries of the last two centuries, replace dopamine or act to reduce anxiety or free radical damage. In addition, ancient Eastern practices such as acupuncture, tai chi, and yoga have proven useful in the amelioration of Parkinson's symptoms. Western medicine, with its "mechanistic" approach, offers no counterparts to these "holistic" modalities.

Although the symptoms of PD have been known for centuries, interest in paralysis agitans grew exponentially following the detailed and widely read essay of James Parkinson. Charcot's re-naming of the "shaking palsy" after James Parkinson was perhaps the catalyst in Western neurology and neuroscience that lead to the consolidation of James Parkinson's observations into a definitive diagnosis- and to a subsequent burgeoning of scientific and clinical research. Some of the contributors to our understanding of PD may not have received credit commensurate with their accomplishments. My hope was to shine a light on these individuals and traditions. In addition to exploring the history of PD as a disease entity, my intent was to show that cultural traditions beyond those of ancient Greece, Western Europe, and the United States, have played a role in understanding and treating this disease. The scientific method has undoubtedly contributed a deeper understanding of the neural, physiologic, genetic, and pharmacologic mechanisms at play in the genesis and progression of PD, but other traditions holding different philosophical approaches, have characterized and treated this disease as well. In reviewing the contribution of Eastern and Western traditions to the understanding and treatment of PD, it becomes apparent that merging these approaches, rather than dichotomizing them, will yield the best results. At present, inquiry continues as new knowledge and cross-fertilization from various disciplines and traditions provide information to be used in treating and perhaps eventually eradicating PD; paralysis agitans; kampavata; chanzheng.

Author contributions: All the authors have accepted responsibility for the entire content of this submitted manuscript and approved submission.

Research funding: None declared.

Employment or leadership: None declared.

Honorarium: None declared.

Competing interests: The funding organization(s) played no role in the study design; in the collection, analysis, and interpretation of data; in the writing of the report; or in the decision to submit the report for publication.

\section{References}

[1] Postuma RB, Berg D, Stern M, Poewe W, Olanow CW, Oertel W, et al. MDS clinical diagnostic criteria for Parkinson's disease. Move Disorders off] Move Disord Soc. 2015;30:1591-601. PubMed PMID: 26474316. 
[2] McMenemey W. James Parkinson 1755-1824: a biographical essay. In: Critchley M, editor. James Parkinson. London: Macmillan, 1955: 1143.

[3] Parkinson ]. An essay on the shaking palsy. London: Sherwood, Neely, and Jones, 1817.

[4] Critchley M. James Parkinson. London: McMillan, 1955.

[5] Coetz CG. Charcot on Parkinson's disease. Move Disorders off] Move Disord Soc. 1986;1:27-32. PubMed PMID: 3332804.

[6] Blonder LX, Slevin JT. Emotional dysfunction in Parkinson's disease. Behav Neurol. 2011 Jan 1;24:201-17. PubMed PMID: 21876260. Pubmed Central PMCID: 3177157. Epub 2011/08/31.eng.

[7] Bereczki D. The description of all four cardinal signs of Parkinson's disease in a Hungarian medical text published in 1690. Parkinsonism Relat Disord. 2010 May;16:290-93. PubMed PMID: 19948422.

[8] Stern C. Did parkinsonism occur before 1817?.] Neurol Neurosurg Psychiatry. 1989 ]un;52:11-12.

[9] Zhang ZX, Dong ZH, Roman CC. Early descriptions of Parkinson disease in ancient China. Arch Neurol. 2006 May;63:782-84. PubMed PMID: 16682554.

[10] Zheng CQ. Therapeutic history of Parkinson's disease in Chinese medical treatises. ] Altern Complementary Med. 2009 Nov;15:1223-30. PubMed PMID: 19922254.

[11] Lee SH, Lim S. Clinical effectiveness of acupuncture on Parkinson disease: a PRISMA-compliant systematic review and meta-analysis. Medicine. 2017 Jan;96:e5836. PubMed PMID: 28099340. Pubmed Central PMCID: 5279085.

[12] Tian T, Sun Y, Wu H, Pei ], Zhang ], Zhang Y, et al. Acupuncture promotes mTOR-independent autophagic clearance of aggregation-prone proteins in mouse brain. Sci Rep. 2016 Jan 21;6:19714. PubMed PMID: 26792101. Pubmed Central PMCID: 4726430.

[13] Li F, Harmer P, Fitzgerald K, Eckstrom E, Stock R, Galver ], et al. Tai chi and postural stability in patients with Parkinson's disease. N Engl ] Med. 2012 Feb 09;366:511-19. PubMed PMID: 22316445. Pubmed Central PMCID: 3285459.

[14] Yang Y, Qiu WQ, Hao YL, Lv ZY, Jiao S], Teng JF. The efficacy of traditional Chinese medical exercise for Parkinson's disease: a systematic review and meta-analysis. PLoS One. 2015;10:e0122469. PubMed PMID: 25830664. Pubmed Central PMCID: 4382160.

[15] Cheung F. TCM: made in China. Nature. 2011 Dec 22;480:S82-3. PubMed PMID: 22190085.

[16] Zijlstra F], Van Den Berg-De Lange I, Huygen F], Klein ]. Anti-inflammatory actions of acupuncture. Mediators Inflamm. 2003 Apr;12:5969. PubMed PMID: 12775355. Pubmed Central PMCID: 1781596.

[17] Ye Y, Zhu W, Wang XR, Yang JW, Xiao LY, Liu Y, et al. Mechanisms of acupuncture on vascular dementia-A review of animal studies. Neurochem Int. 2017 Jul;107:204-10. PubMed PMID: 28034725.

[18] Bower ]E, Irwin MR. Mind-body therapies and control of inflammatory biology: a descriptive review. Brain Behav Immun. 2016 ]an;51:111. PubMed PMID: 26116436. Pubmed Central PMCID: 4679419.

[19] Pan W, Liu ], Chen X, Wang Q, Wu Y, Bai Y, et al. A practical consensus guideline for the integrative treatment of Parkinson's disease in Shanghai. China Integr Med Int. 2015;2:56-62. Epub September 12, 2015

[20] Mishra L, Singh BB, Dagenais S. Ayurveda: a historical perspective and principles of the traditional healthcare system in India. Altern Ther Health Med. 2001 Mar;7:36-42. PubMed PMID: 11253415.

[21] Manyam BV. Paralysis agitans and levodopa in "Ayurveda": ancient Indian medical treatise. Move Disorders off] Move Disord Soc. 1990;5:47-48. PubMed PMID: 2404203.

[22] Ovallath S, Deepa P. The history of Parkinsonism: descriptions in ancient Indian medical literature. Move Disorders off] Move Disord Soc. 2013 May;28:566-68. PubMed PMID: 23483637.

[23] Vaidya AB, Rajagopalan TC, Mankodi NA, Antarkar DS, Tathed PS, Purohit AV, et al. Treatment of Parkinson's disease with the cowhage plant-Mucuna pruriens Bak. Neurol India. 1978 Dec;26:171-76. PubMed PMID: 753996.

[24] Vaidya RA, Sheth AR, Aloorkar SD, Rege NR, Bagadia VN, Devi PK, et al. The inhibitory effect of the cowhage plant-Mucuna pruriens-and L-dopa on chlorpromazine-induced hyperprolactinaemia in man. Neurol India. 1978 Dec;26:177-78. PubMed PMID: 753997.

[25] Damodaran M, Ramaswamy R. Isolation of I-3:4-dihydroxyphenylalanine from the seeds of Mucuna pruriens. Biochem ]. 1937 Dec;31:2149-52. PubMed PMID: 16746556. Pubmed Central PMCID: 1267191.

[26] Hussain GaM B. Mucuna pruriens Proves more effective than L-DOPA in Parkinson's disease animal model. Phytotherapy Res. 1997;11:419-23.

[27] Katzenschlager R, Evans A, Manson A, Patsalos PN, Ratnaraj N, Watt H, et al. Mucuna pruriens in Parkinson's disease: a double blind clinical and pharmacological study. ] Neurol Neurosurg Psychiatry. 2004 Dec;75:1672-77. PubMed PMID: 15548480. Pubmed Central PMCID: 1738871

[28] Hornykiewicz O. L-DOPA: from a biologically inactive amino acid to a successful therapeutic agent. Amino Acids. 2002;23:65-70. PubMed PMID: 12373520.

[29] Ni M, Mooney K, Signorile JF. Controlled pilot study of the effects of power yoga in Parkinson's disease. Complement Ther Med. 2016 Apr:25:126-31. PubMed PMID: 27062960.

[30] Roland KP. Applications of yoga in Parkinson's disease: a systematic literature review. ] Parkinsonism Restless Legs Syndrome. 2014;4:18.

[31] SchmalzI L, Kerr CE. Editorial: neural mechanisms underlying movement-based embodied contemplative practices. Front Hum Neurosci. 2016;10:169. PubMed PMID: 27199700. Pubmed Central PMCID: 4844845.

[32] Horowski R, Horowski L, Vogel S, Poewe W, Kielhorn FW. An essay on Wilhelm von Humboldt and the shaking palsy: first comprehensive description of Parkinson's disease by a patient. Neurology. 1995 Mar;45:565-68. PubMed PMID: 7898719.

[33] Goetz CG. The history of Parkinson's disease: early clinical descriptions and neurological therapies. Cold Spring Harb Perspect Med. 2011 Sep;1:a008862. PubMed PMID: 22229124. Pubmed Central PMCID: 3234454.

[34] Cowers WR. A manual of diseases of the nervous system. Philadelphia, PA: Blakiston Son and Co., 1888.

[35] Critchley M. Sir William Gowers, 1845-1915; a biographical appreciation. London: Heinemann, 1949: 118.

[36] Lees A], Selikhova M, Andrade LA, Duyckaerts C. The black stuff and Konstantin Nikolaevich Tretiakoff. Move Disorders off] Move Disord Soc. 2008 Apr 30;23:777-83. PubMed PMID: 18383531. 
[37] Vogt M. The concentration of sympathin in different parts of the central nervous system under normal conditions and after the administration of drugs. J Physiol. 1954 Mar 29;123:451-81. PubMed PMID: 13152692. Pubmed Central PMCID: 1366219.

[38] Greenfield JG. Pathology of Parkinson's disease. In: Critchley M, editor. James Parkinson. London: MacMillan, 1955: 219-43.

[39] Ehringer HHO. Verteilung von Noradrenalin und Dopamin (3-Hydroxytyramin) im Cehirn des Menschen und ihr Verhalten bei Erkrankungen des extrapyramidalen Systems. Klin Wochenschr. 1960;38:1236-39.

[40] Spillantini MG, Schmidt ML, Lee VM, Trojanowski JQ, Jakes R, Goedert M. Alpha-synuclein in Lewy bodies. Nature. 1997 Aug 28;388:83940. PubMed PMID: 9278044.

[41] Braak H, Del Tredici K, Rub U, De Vos RA, Jansen Steur EN, Braak E. Staging of brain pathology related to sporadic Parkinson's disease. Neurobiol Aging. 2003 Mar-Apr;24:197-211. PubMed PMID: 12498954. Epub 2002/12/25.eng.

[42] Burke RE, Dauer WT, Vonsattel JP. A critical evaluation of the Braak staging scheme for Parkinson's disease. Ann Neurol. 2008 Nov;64:485-91. PubMed PMID: 19067353. Epub 2008/12/11.eng.

[43] Jellinger KA. A critical evaluation of current staging of alpha-synuclein pathology in Lewy body disorders. Biochim Biophys Acta. 2009 Jul;1792:730-40. PubMed PMID: 18718530.

[44] Holtz PHR, Lüdtke K. Fermentativer Abbau von LDioxyphenylalanin (Dopa) durch Niere. Naunyn-Schmiedeberg's. Arch Exp Path Pharmak. 1938;191:87-118.

[45] Fahn S. The medical treatment of Parkinson disease from James Parkinson to George Cotzias. Move Disorders off] Move Disord Soc. 2015;30:4-18 (Epub was Dec 2014).

[46] Montagu KA. Catechol compounds in rat tissues and in brains of different animals. Nature. 1957 Aug 3;180:244-45. PubMed PMID: 13451690.

[47] Raab W, Gigee W. Concentration and distribution of "encephalin" in the brain of humans and animals. Proc Soc Exp Biol Med Soc Exp Biol Med. 1951 Jan;76:97-100. PubMed PMID: 14816401.

[48] Weil-Malherbe H, Bone AD. Intracellular distribution of catecholamines in the brain. Nature. 1957 Nov 16;180:1050-51. PubMed PMID: 13483601.

[49] Holtz PBH, Westermann E, Wezler E. Beeinflussung der Evipannarkose durch Reserpin. Iproniazid Biogene Amine Arch Exp Path Pharmakol. 1957;231:333-48.

[50] Bertler A, Rosengren E. Occurrence and distribution of dopamine in brain and other tissues. Experientia. 1959 ]an 15;15:10-11. PubMed PMID: 13619664

[51] Hornykiewicz O. The action of dopamine on the arterial blood pressure of the guinea-pig. Br] Pharmacol Chemother. 1958 Mar;13:91-94. PubMed PMID: 13523142. Pubmed Central PMCID: 1481693.

[52] Sano I, Gamo T, Kakimoto Y, Taniguchi K, Takesada M, Nishinuma K. Distribution of catechol compounds in human brain. Biochim Biophys Acta. 1959 Apr;32:586-87. PubMed PMID: 14441532.

[53] Carlsson A, Lindqvist M, Magnusson T, Waldeck B. On the presence of 3-hydroxytyramine in brain. Science. 1958 Feb 28;127:471. PubMed PMID: 13529006.

[54] Carlsson A. The occurrence, distribution and physiological role of catecholamines in the nervous system. Pharmacol Rev. 1959 Jun;11:490-93. PubMed PMID: 13667431.

[55] Carlsson A. A half-century of neurotransmitter research: impact on neurology and psychiatry. Nobel lecture. Biosci Rep. 2001 Dec;21:691710. PubMed PMID: 12166820.

[56] Lees A], Tolosa E, Olanow CW. Four pioneers of L-dopa treatment: arvid Carlsson, Oleh Hornykiewicz, Ceorge Cotzias, and Melvin Yahr. Move Disorders off] Move Disord Soc. 2014 Dec 8. PubMed PMID: 25488030.

[57] Foley P. The L-DOPA story revisited. Further surprises to be expected?. ] Neural Transm Supplementum. 2000;60:1-20. PubMed PMID: 11205132.

[58] Sano I. Biochemistry of the extrapyramidal system Shinkei Kennkyu No Shinpo, Advances in Neurological Sciences. (ISSN 0001-8724) Tokyo, October 1960;5:42-48. Parkinsonism Relat Disord. 2000 Jan;6:3-6. PubMed PMID: 18591145.

[59] Birkmayer W, Hornykiewicz O. Der L-Dioxyphenylalanin (=DOPA)-Effekt bei der Parkinson-Akinese. Wien Klin Wochenschr. 1961;73:78788.

[60] Barbeau A, Murphy CF, Sourkes TL. Excretion of dopamine in diseases of basal ganglia. Science. 1961 May 26;133:1706-07. PubMed PMID: 13686753.

[61] Barbeau A, Sourkes TL, Murphy GF. Les catécholamines dans la maladie de Parkinson. In: De Ajuriaguerra ], editor. Monoamines et Système Nerveux Central. Ceneva: Ceorg et Cie, 1962: 247-62.

[62] Hornykiewicz O. Die topische Lokalisation und das Verhalten von Noradrenalin und Dopamin (3-Hydroxytyramin) in the Substantia nigra des normalen und Parkinsonkranken Menschen. Wien Klin Wochenschr. 1963;75:309-12.

[63] Hornykiewicz O. The discovery of dopamine deficiency in the parkinsonian brain. J Neural Transm Supplementum. 2006;70:9-15. PubMed PMID: 17017502.

[64] Cotzias CC, Van Woert MH, Schiffer LM. Aromatic amino acids and modification of Parkinsonism. N Engl ] Med. 1967 Feb 16;276:374-79. PubMed PMID: 5334614.

[65] Cotzias CC, Papavasiliou PS, Gellene R. Modification of Parkinsonism-chronic treatment with L-dopa. N Engl ] Med. 1969 Feb 13;280:33745. PubMed PMID: 4178641

[66] Tang LC. A personal and scientific biography of Dr Ceorge C. Cotzias. Neurotoxicology. 1984 Spring;5:5-12. PubMed PMID: 6425745.

[67] Yahr MD, Duvoisin RC, Schear M], Barrett RE, Hoehn MM. Treatment of Parkinsonism with levodopa. Arch Neurol. 1969 Oct;21:343-54. PubMed PMID: 5820999.

[68] Hoehn MM, Yahr MD. Parkinsonism: onset, progression and mortality. Neurology. 1967 May;17:427-42. PubMed PMID: 6067254

[69] Hoehn MM, Yahr MD. Parkinsonism: onset, progression and mortality. Neurology. 1967;17:427-42.

[70] Fahn S. A new look at levodopa based on the ELLDOPA study. ] Neural Transm Supplementum. 2006;70:419-26. PubMed PMID: 17017562 . 